\title{
Hist. Aug., HADR. 13, 6: LA CONSAGRACIÓN DEL TEMPLO DE ZEUS OLIMPIO. ADRIANO Y LA INTEGRACIÓN RELIGIOSA DEL IMPERIO \\ Hist. AUg., HADR. 13.6: THE CONSECRATION of THE TEMPle of Zeus Olympios. Hadrian and \\ THE RELIGIOUS INTEGRATION OF THE EMPIRE
}

\author{
Juan Manuel Cortés Copete \\ Universidad Pablo de Olavide de Sevilla \\ JMCORCOP@UPO.ES
}

\section{RESUMEN}

Hist. Aug., Hadr. 13, 6 es, junto con Cass. Dio, LXIX 16, 1-2, nuestro único testimonio literario del viaje de Adriano por Oriente entre los años 128 y 134. Hist. Aug., Hadr. 13,6 recoge, de manera somera y comprimida, algunos de los acontecimientos cruciales de este viaje. Uno de estos fue la consagración del templo de Zeus Olimpio en Atenas. La Historia Augusta parece situar la consagración en 128 aunque los testimonios epigráficos la fechan, indudablemente, en 132. Sobre esta discrepancia, Weber, seguido por Graindor, articuló la explicación una doble ceremonia: en el 128, la dedicatio, y en el 132, la consecratio. He tratado de

\section{Abstract}

Hist. Aug., Hadr. 13, 6 is, together with Cass. Dio, LXIX 16, 1-2, the only literary evidence for Hadrian Eastern journey during years 128 y 134 AD. Hist. Aug., Hadr. 13, 6 relates briefly some of the crucial happenings which took place during the journey, such as the consecration of the temple of Zeus Olympios in Athens. The Historia Augusta appears to place the consecration during the year $128 \mathrm{AD}$, although the epigraphic evidence unquestionably dates it to $132 \mathrm{AD}$. Weber attempted to explain this discrepancy by means of a double ceremony, a dedicatio in $128 \mathrm{AD}$ and the consecration in $132 \mathrm{AD}$. I have attempted to demon-

\footnotetext{
* Este estudio se ha realizado dentro del proyecto "Adriano y la integración de la diversidad regional. Una perspectiva histórica e historiográfica” (HAR2015-65451-C2-1-P MINECO/FEDER).
} 
demostrar que esta interpretación, aceptada como comunis opinio, es incorrecta y que las ceremonias religiosas en el templo de Zeus Olimpio tuvieron lugar en 132. La HA procedió a comprimir la narración y a usar diferentes términos, dedicatio y consecratio, por una cierta voluntad de estilo según los gustos del s. IV d.C. El templo de Adriano que se construyó en Éfeso sirve como referencia para la argumentación. Por último, sostengo que el templo de Zeus Olimpio fue importante porque con la ceremonia del 132 el emperador superaba la barrera del suelo religioso romano y el no religioso de las provincias. El templo de Zeus Olimpio, el primero consagrado por un emperador en el suelo de una ciudad libre, fue capaz de congregar no sólo a los griegos sino también a los ciudadanos romanos y las colonias de oriente. strate how this interpretation, accepted as comunis opinio, is incorrect and that the religious ceremonies in the temple of Zeus Olympios took place in $132 \mathrm{AD}$. The HA tends to compress the narration and to use different terms, dedicatio and consecratio, due to the stylistic taste typical of IV century AD. An additional element in favour of this argumentation is the temple of Hadrian that was erected in Ephesos. Finally, the article stresses out the importance of the temple of Zeus Olympios due to the fact that with the ceremony of $132 \mathrm{AD}$ the emperor reaches beyond the Roman religious soil and the non-religious provincial ones. The temple of Zeus Olympios, the first one to be consecrated by an emperor outside of Rome and within a free city, represented a unifying factor not only among the Greeks but also with the Roman citizens and the Eastern colonies.
Palabras Clave

Adriano, Atenas, Éfeso, Olimpieion, Culto Imperial, Integración religiosa del Imperio

\section{KEY WORDS}

Hadrian, Athens, Ephesus, Olympieion, Imperial cult, Religious integration 
DE LA ESCASEZ DE TESTIMONIOS SOBRE EL PROCESO que condujo tanto a la exaltación divina de Adriano en Oriente como a la fundación del Panhelenion, nos salvan dos breves pasajes en las fuentes antiguas: Historia Augusta 13, 6 y Casio Dion LXIX 16, 1-2. ${ }^{1}$ Ambos son textos problemáticos que, además de reseñar algunos de los extraordinarios acontecimientos ocurridos en Atenas y otros lugares del Oriente durante la última década del reinado del emperador, generan dudas sobre sus posibles interpretaciones. Cada uno de ellos exigiría, ciertamente, un comentario minucioso y detallado. En el presente estudio me propongo realizar un acercamiento a lo referido en la HA, Vita Hadriani 13, 6. ${ }^{2}$ Dice así el texto transmitido:

Denique cum post Africam Romam redisset, statim ad orientem profectus per Athenas iter fecit atque opera quae apud Athenienses coeperat dedicauit, ut Iouis Olympii aedem et aram sibi, eodemque modo per Asiam iter faciens templa sui nominis consecrauit.

Luego, como después de África volviese a Roma, tras partir inmediatamente para Oriente, hizo el viaje por Atenas y dedicó las obras que había comenzado entre los atenienses, como el templo de Júpiter Olimpio y un altar para sí mismo; y de ese mismo modo, cuando hizo el viaje por Asia consagró unos templos en su propio nombre.

El trabajo fundamental de Weber, seguido por los esfuerzos de Graindor y Follet, a los que habría que sumar los nuevos argumentos que aportaron Halfmann y Birley, han contribuido a definir una suerte de vulgata de interpretación del pasaje. ${ }^{3}$ Este acuerdo, universalmente aceptado tanto en sus líneas principales como en muchos de sus detalles, nace de la asunción de la hipótesis de que el relato, o parte del relato, de la Historia Augusta posee un cierto valor cronológico. Usualmente se ha

1. Kuhlmann, 2002, pp. 81-87, 151-153.

2. El comentario de Fündling, 2006, pp. 648-653.

3. Weber, 1907; Graindor, 1934; Follet, 1976; Halfmann, 1986; Birley, 1997. 
considerado que la Vida de Adriano, hasta mitad del capítulo 14, mantuvo una ordenación cronológica de la vida y obra del emperador. ${ }^{4}$ A partir de 14, 8 la Vita habría abandonado ese armazón temporal para emprender una narración más analítica, si se quiere ser benévolo en el juicio, o dispuesta por la simple asociación de ideas, si se prefiere ser riguroso. Admitiendo que 13, 6 forma parte de ese primer bloque de ordenación cronológica, podría proporcionar la información necesaria para reconstruir la secuencia temporal de los sucesos que narra. Y así se ha hecho.

\section{Las fechas del viaje a África y al Oriente}

El viaje a África del emperador, con el que se inicia el pasaje, tuvo lugar en los meses centrales del año $128 .{ }^{5}$ En aquel mismo año Adriano había aceptado, finalmente, el título de Pater Patriae. ${ }^{6}$ Este honor se le había otorgado por primera vez tan pronto como llegó al trono imperial, en los últimos meses del año 117, pero en aquel entonces renunció a él. ${ }^{7}$ La Historia Augusta sugiere, en el mismo lugar, que hubo un segundo intento, también fallido, de concederle el título. L. Perret hizo la propuesta de que la mejor ocasión para este nuevo ofrecimiento podría haber sido la inauguración de las obras del templo de Venus y Roma, el 21 de abril del año $121 .{ }^{8}$ Desgraciadamente, no hay ninguna evidencia que pueda apoyar esta propuesta, a pesar de la trascendencia que para el programa adrianeo tuvo aquella fecha de inauguración. ${ }^{9}$ Transcurridos los primeros diez años de reinado, en la primavera del 128, una década después del primer ofrecimiento, las circunstancias habían cambiado y el emperador aceptó por fin el título de Pater Patriae. ${ }^{10}$ Se ha sostenido, asimismo, que la aceptación definitiva del título en el año 128 estuvo vinculada a la consagración del templo de

4. Callu, 1992, pp. 4-6, denomina a esta primera sección ordenada cronológicamente "la suite événementielle".

5. Birley, 1997, pp. 203-214.

6. Hieron., Chron. 199 Helm: Imperator Hadrianus Pater Patriae appellatur.

7. La asunción temprana del honor pudo estar vinculada a una adopción y sucesión bien planificadas que, sin embargo, no pudieron ejecutarse en todos sus términos por la muerte inesperada de Trajano en Selino, durante su viaje de regreso a Roma: Cortés Copete, 2014; Hist. Aug., Hadr. 6, 4.

8. HA, Hadr. 6, 4: et iterum postea distulit. Cf. Perret, 1929, pp. 66-70.

9. Este fue el momento de trasformación de las tradicionales Parilia en el dies natalis Urbis, la fiesta del nacimiento de Roma que celebraban todos los presentes en la capital, sin distinción de su origen. Cf. Graf, 2015, pp. 93-95; Athen., VIII 63, 361F.

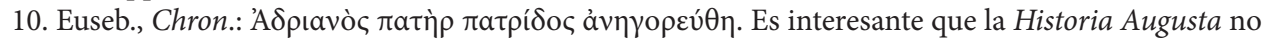
mencione la asunción definitiva del honor por Adriano. 
Venus y Roma. ${ }^{11}$ A pesar del atractivo de esta propuesta, las evidencias arqueológicas tienden a situar esta ceremonia de consagración en los años finales del reinado, ya en la década de los $130 .{ }^{12}$ Sea como fuere, el título de Pater Patriae se ha convertido para nosotros en una de las referencias cronológicas más seguras del reinado, especialmente cuando en los documentos epigráficos y numismáticos no se cita la potestad tribunicia, y habida cuenta de que el emperador nunca volvió a asumir el consulado tras haberlo desempeñado por tercera vez en el año 119.

El viaje tuvo como destinos principales Sicilia, África y Mauritania. ${ }^{13}$ El monumento de Lambesis, con los discursos de Adriano ante el ejército, sitúa al emperador en África a principios del mes de julio del $128 .{ }^{14}$ Es evidente que tuvo que acelerar vivamente el paso, y la navegación, para regresar a Roma, siquiera fugazmente, antes de poner rumbo a Atenas, tal y como recuerda la Historia Augusta. A Atenas llegó antes de que terminara el año efébico de 127-128, año que cumplía en agosto de esa última fecha. ${ }^{15}$ Vistas así las cosas, se entiende a la perfección que la Historia Augusta utilizara el adverbio statim, "inmediatamente" para referirse a la partida hacia Oriente.

Teniendo siempre en mente las dificultades que debe sortear cualquier intento de establecer una cronología precisa en la Antigüedad, parece evidente que el emperador volvió a pasar el invierno del año 128-129 en Atenas. ${ }^{16}$ Tal y como había hecho en el año 124-125, ahora en 128-129 disfrutó del descanso y de temperado clima ateniense durante los rigurosos meses del invierno. Fue este el tiempo de proceder a la segunda iniciación en los Misterios Eleusinos, segunda si no se cuenta aquella primera iniciación en los misterios menores del año 112. Fue entonces, en 128, cuando Adriano alcanzó el grado más alto entre los iniciados, el grado de epoptés, "el que ha visto.".

11. Perret, 1929, pp. 72-73. Esta propuesta encontró más tarde apoyo en la hipótesis de Turcan, 1964, pp. 42-55, de que el templo fue consagrado en 128 en virtud de una serie numismática de Severo Alejandro, del año 227, que podría estar conmemorando los cien años de su consagración.

12. Boatwrigh, 1987, pp. 123-124; Calandra, 1996, pp. 72-76.

13. AE 1957, 135: inscripción en honor a T. Caesernio Macedo, comiti per Siciliam, Afric(am), Mauret(aniam).

14. Syme, 1988, p. 162. En los primeros días de Julio el emperador pronunciaba sus discursos en Lambesis: Le Bohec, 2003, pp. 81, 90, 95, textos 2, 6, 8 respectivamente.

15. IG II $2040=$ SEG 34, 156. Graindor, 1934, p. 37. El catálogo está fechado en 127-128, en el cuarto

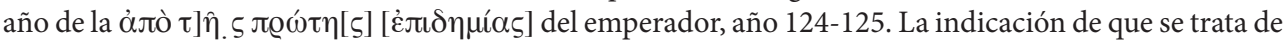
la primera estancia indica, obviamente, que ya existía una segunda. Follet, 1976, pp. 55, 108. Halfmann, 1986, pp. 203-204, asegura, prudente, que había llegado a Atenas antes de octubre de 128.

16. Hieron., Chron. 200 (Helm): Hadrianus Athenis hiemem exigens Eleusina invisit.

17. Cass. Dio, LXIX 11, 1. Graindor, 1934, p. 38; Geagan, 1979, pp. 394-395. 
Dos cartas casi idénticas del propio emperador nos permiten saber cuándo, y desde qué puerto, abandonó Atenas para continuar su viaje hacia Oriente. Fechadas en su decimotercera potestad tribunicia, es decir aquella que discurre desde diciembre del año 128 hasta el mismo mes del año 129, estas cartas imperiales dirigidas a la ciudad de Éfeso pretendían apoyar la pretensión de los navieros Erastos y Filokirios de ser admitidos en la Gerusía de la ciudad jonia. En ellas Adriano recuerda cómo, en aquellos días, Erastos y Filokirios lo habían acompañado con sus barcos desde Eleusis hasta la ciudad asiática. ${ }^{18}$ De este modo se confirmaba, con pruebas irrefutables, que el pasaje de la Historia Augusta estaba siguiendo la secuencia del itinerario adrianeo: per Asiam iter faciens. Si tuviéramos que conceder alguna credibilidad a Juan Malalas - y cuando trata asuntos vinculados con Antioquía es bueno hacerlo -, Adriano estaba el 23 de junio del año 129 en la ciudad siria para celebrar la Fiesta de las Fuentes. ${ }^{19}$ Un margen de dos meses sería prudente para ubicar su salida de Atenas en dirección al continente asiático y recorrer el camino hasta la capital de Siria. Es decir, el emperador habría embarcado en Eleusis en marzo o abril del año 129 con destino a Éfeso, ciudad que ya había visitado en el 124. Y todavía habría de volver una vez más a la ciudad griega.

\section{Los TEMPlos de Asia y SU CONSAgRaCión. El CASO de ÉfESo}

Como resulta evidente, el esfuerzo minucioso de todos aquellos ilustres historiadores y epigrafistas se ha visto recompensado con el acuerdo entre el pasaje de la biografía del emperador y las evidencias dispersas en crónicas tardías y epígrafes repartidos por el Imperio. Pero este acuerdo sobre el itinerario y sobre las fechas, insólitamente precisas para la Antigüedad, no puede mantenerse en lo que se refiere a las actividades que, según la Historia Augusta, el emperador llevó a cabo en Oriente. Para el biógrafo imperial, para el conglomerado de autores que es nuestro relato de la Vita Hadriani, el emperador se entretuvo en Atenas, primero, dedicando el templo de Zeus Olimpio y un altar a sí mismo (opera... dedicauit, ut Iouis Olympii aedem et aram sibi), y en las ciudades de Asia, después, consagrando templos en su nombre (templa sui nominis consecrauit). Sin embargo, y a diferencia de lo que ocurre con las distintas etapas del viaje, las evidencias epigráficas no concuerdan con esta narración. Será bueno comenzar por analizar lo hecho en Asia.

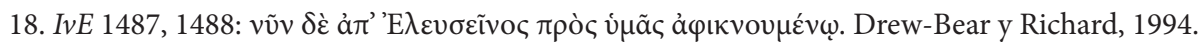

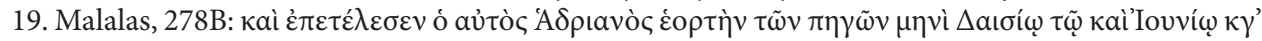
(23 de junio). Weber, 1907, pp. 121, 231-232. 
Los comentaristas han sido unánimes al entender que el emperador fue abriendo templos de culto imperial por las ciudades de la provincia de Asia, ciudades que recibían así el título de Neocoros. Esmirna, Cícico, Éfeso y, quizás, Sardes y Pérgamo parecen haber sido las ciudades agraciadas.$^{20}$ No obstante, cuando la epigrafía lo permite, descubrimos inmediatamente que el pasaje de la Historia Augusta estaba haciendo una exposición somera y comprimida en el tiempo, haciendo que numerosos y diferentes acontecimientos que se repartieron a lo largo de la última década de vida de Adriano aparezcan concentrados durante la visita del año 129, camino de Siria, Palestina y Egipto. Estudiemos el caso de Éfeso, dotado de una preciosa documentación epigráfica paralela a la noticia de la Historia Augusta.

La ciudad de Éfeso había recibido la autorización del gobierno romano para levantar un templo al emperador en tiempos de Nerón. Las dificultades políticas en que acabó el reinado de aquel primer emperador filoheleno impidieron que el santuario le fuera consagrado, de tal manera que fueron los emperadores Flavios, tanto Vespasiano como el mismo Domiciano más tarde, quienes recibieron culto allí bajo la genérica denominación de Augustos. ${ }^{21}$

Esta situación se mantuvo inalterada hasta, al menos, el año 130-131. Fue en este año cuando un notable de la ciudad, Claudio Verulano Marcelo, embelleció con revestimientos de mármol las palestras del gimnasio del puerto, construido en tiempos de Domiciano. ${ }^{22} \mathrm{El}$ adorno quizás se hizo ante la noticia de una nueva visita del emperador, a quien, en compañía de Artemisa, se dedicó la obra. La monumental inscripción así lo refería (IVE, 430):

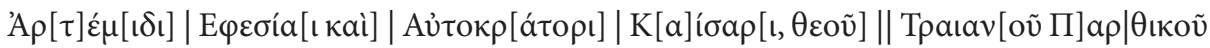

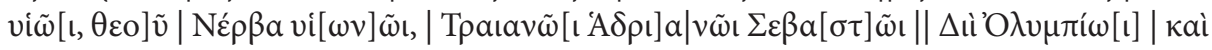

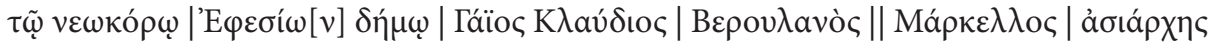

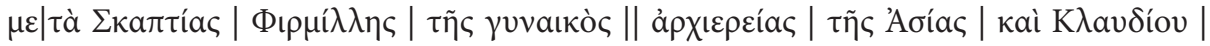

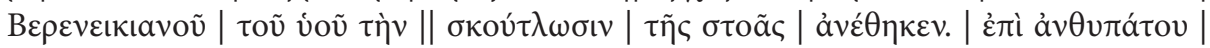

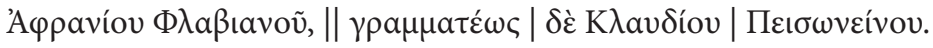

A Artemisa Efesia y al Emperador César Trajano Adriano Augusto, hijo del dios Trajano Pártico, nieto del dios Nerva, Zeus Olimpio, y al pueblo neocoro de los Efesios, Gayo Claudio Verulano Marcelo, asiarca, en compañía de Scaptía Firmila, su mujer, sacerdo-

20. Burrell, 2004, pp. 42-48 (Esmirna), 86-94 (Cícico), Éfeso (66-70), 100 (Sardes), 27-30 (Pérgamo), siendo dudosas estas dos últimas ciudades. Para Pérgamo: Müller, 2009.

21. Burrell, 2004, pp. 60-66.

22. Halfmann, 2004, p. 99. 
tisa de Asia, y de Claudio Vereniciano, su hijo, dedicó el adorno de mármol de la estoa. Bajo el proconsulado de Afranio Flaviano y siendo secretario Claudio Pisonino

La inauguración de la estoa está bien datada gracias al proconsulado de Afranio Flaviano, quien gobernó Asia en el año $130-131 .{ }^{23}$ En esa fecha todavía la ciudad de Éfeso aparecía en las inscripciones oficiales como Neocoros, es decir, como guardiana de aquel primer templo de época Flavia y sin mención alguna a la concesión de un segundo templo de culto imperial. Fue precisamente ese año, el 131, cuando Adriano volvió a pisar tierra asiática después de su viaje por Siria y Egipto. ${ }^{24}$ Cuatro basas de estatuas del emperador en la ciudad de Phaselis, dos dedicadas por la propia ciudad y las otras dos levantadas por las vecinas Akalisis y Coridalas, confirman que la llegada del emperador se produjo en aquel año y por mar, desembarcando en la costa de

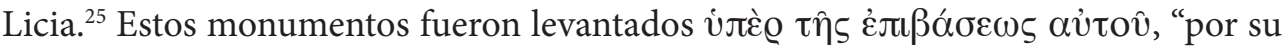
arribada". Los epígrafes de dos de esas basas, mejor conservados, nos proporcionan la fecha pues citan la decimoquinta potestad tribunicia, de diciembre del año 130 hasta diciembre de 131. Es fácil, entonces, suponer que el emperador llegó a Phaselis y de allí, ya fuera de nuevo por mar o ahora ya por tierra, se encaminó hacia Éfeso, teniendo en mente que su destino final habría de volver a ser Atenas. ${ }^{26}$

En Éfeso, durante esta tercera y última visita, Adriano no sólo habría tenido ocasión de admirar la nueva estoa del gimnasio sino, quizás incluso, de asistir a su inauguración. Como es lógico, también tuvo ocasión de reunirse con las autoridades de la ciudad y sus notables. Fue probablemente entonces cuando la ciudad pidió el permiso para construir un nuevo templo de culto imperial. ${ }^{27}$ Una inscripción en honor a un notable local, Tiberio Claudio Pisón Diophante, desvelaba, años después, que este aristócrata había actuado como portavoz de la ciudad de Éfeso y del Koinón Asiático ante el emperador, consiguiendo, sin duda gracias a sus habilidades retóricas, el ansiado permiso imperial. El monumento en honor a Diophante fue levantado al final de su carrera política, cuando ya reinaba Antonino Pío, y en él se describe al aristócrata efesio como "el que primero pidió y consiguió de manos del divino Adria-

23. Habicht, 1969, pp. 53-59, ha identificado a los procónsules de Asia de los años 128-129, 129-130 y 131-132. Sólo queda el año 130-131 para el desempeño de Afranio Flaviano. Bowie, 1971, pp. 137-141.

24. Tercera visita a Éfeso en el viaje de regreso de Egipto, en 131: Halfmann, 1986, pp. 199-201.

25. TAM II 1, 191-194.

26. Birley, 1997, p. 261.

27. Burrel, 2002-2003, pp. 44-48. 


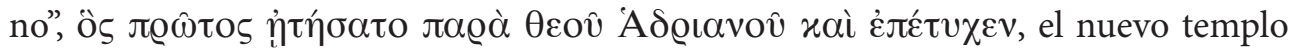

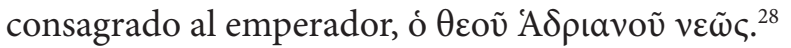

Una inscripción ateniense permite establecer el terminus ante quem para la concesión de la segunda Neokoría de Éfeso. Entre los monumentos que se levantaron en Atenas en el año 132, datados en la decimosexta potestad tribunicia del emperador, ${ }^{29}$ se conserva aquel que levantó la ciudad de Éfeso. ${ }^{30} \mathrm{Y}$ allí, a pesar del estado fragmentario de la inscripción, podemos leer el nuevo título de la ciudad:

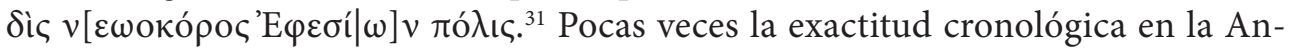
tigüedad puede ser mayor. Entre la segunda mitad del año 130, límite más antiguo fijado por la inscripción de la estoa efesia en la que todavía la ciudad es simplemente Neokoros, y la primavera de 132, terminus ante quem establecido por esta inscripción de Atenas, la ciudad de Éfeso recibió su segunda neocoría de manos de Adriano. No habría mejor ocasión que la que proporcionaba la tercera última visita del emperador a Éfeso, durante el año 131.

Una vez conseguido el beneplácito imperial, y posiblemente también el acuerdo del Senado necesario para tales menesteres, empezaron las obras de construcción del nuevo templo, que se prolongaron durante algunos años. Tenemos algún testimonio que nos permite atisbar el lapso de tiempo que medió entre el permiso y la construcción. En el año 134-135 (de nuevo la fecha la proporciona el procónsul de Asia, el mismo que habría de llegar a ser emperador bajo el nombre de Antonino Pío) se consagró un monumento a Sabina. ${ }^{32}$ La ciudad de Éfeso utilizó entonces el título

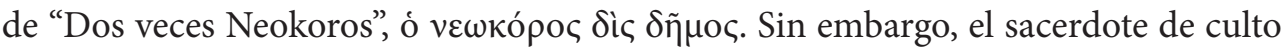
imperial, que también estaba encargado del monumento en honor a la emperatriz,

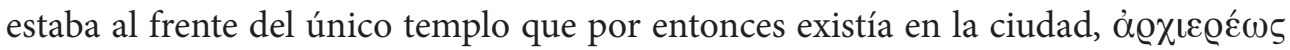

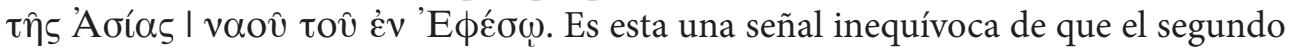

28. IvE 428. En dos ocasiones se habla en esta inscripción del dios Adriano ( $\theta \varepsilon$ cov Adplavoṽ), indicio de que se levantó el monumento tras la apoteosis romana del emperador. Burrell, 2004, p. 66; Bowie, 2012, p. 269; Halfmann, 2004, p. 99.

29. La fecha ( $16^{\text {a }}$ potestad tribunicia, de diciembre de 131 a diciembre de 132 d.C.) la proporciona el texto latino de las basas de unas estatuas del emperador levantadas por algunas colonias romanas: Dione (IG II 2289 ); Alejandría Troas (CIL III 7282); Antioquía de Pisidia (CIL III 7283).

30. Las basas de las estatuas que las ciudades griegas levantaron al emperador en el templo de Zeus Olimpio no tienen fecha. Se ubican en el año 132 d.C. por analogía a las inscripciones latinas citadas en la nota anterior.

31. IG $\mathrm{II}^{2} 3297$.

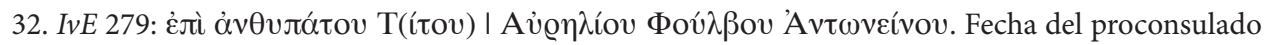
de Asia: Eck, 1970, p. 210. 
templo, aquel para el que se había conseguido el permiso en el año 131, todavía no estaba terminado en el año 134-135.

No sabemos cuántos años más tardó en completarse la obra de aquel templo, que fue consagrado finalmente por aquel mismo Tiberio Claudio Pisón Diophante que había obtenido el permiso para su construcción. En el monumento que un poco más arriba citaba, se le calificaba como el sacerdote de los dos templos, bajo

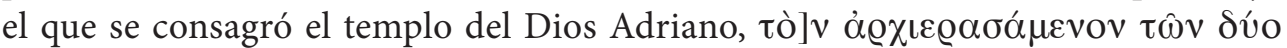

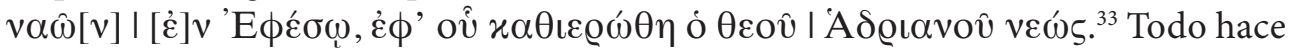
pensar que el monumento de Diophante se levantó tras el 138, tras la muerte de Adriano, y cabe la posibilidad incluso de que el templo no se hubiese terminado antes del fallecimiento del emperador. ${ }^{34}$

De este breve pero clarificador relato, parece evidente que la Historia Augusta tiende a concentrar en un solo momento procesos que ocupaban varios y, en ocasiones, largos años, procesos tales como la construcción de un templo de culto imperial una vez que se había conseguido el derecho a levantarlo y gestionarlo. La secuencia ordenada de los acontecimientos podría quedar como sigue. Cuando el emperador Adriano llegó por tercera y última vez a la ciudad de Éfeso, en la segunda mitad del año 131, la ciudad sólo tenía un antiguo templo de culto imperial que otorgaba a su demos la prestigiosa condición de Neocoros. Durante aquella última estancia, Diophante se las arregló para convencer al emperador de que les concediera el permiso para levantar un segundo templo de culto imperial dedicado al propio Adriano. La concesión de aquel permiso fue acompañada de una segunda Neocoría que ya se hizo pública en el monumento que Éfeso erigió en el recinto del santuario de Zeus Olimpio en Atenas en el año 132. No obstante, las obras del nuevo templo efesio avanzaron con cierta parsimonia y así, en el año 134-135, aunque la ciudad se proclamara dos veces neocoros, sólo tenía un templo de culto imperial en servicio, tal y como se atestigua por el monumento de Sabina. En una fecha indeterminada, pero en las cercanías de la muerte del emperador, aquel mismo Diofante que consiguió el permiso para el segundo templo imperial lo consagró y puso en servicio. Desde entonces Éfeso fue dos veces neocoros y tuvo dos templos imperiales, el último de ellos dedicado a Adriano.

33. IvE 428.

34. La última frase del monumento invita ciertamente a pensar que el emperador ya había fallecido

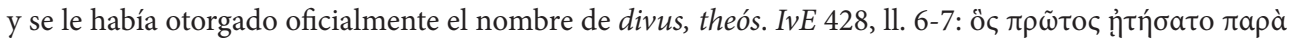

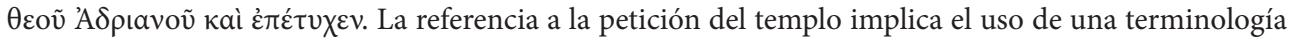
institucional romana, de la que la divinidad del emperador estaba ausente hasta después de la apoteosis. Cortés Copete, 2017b. 
Esta compresión temporal de los acontecimientos en la biografía de Adriano podría ser considerada como un mecanismo lógico y natural de los procesos de abreviación narrativa. Sin embargo, en el pasaje que comentamos de la Historia Augusta se incurrió en una segunda confusión quizás más significativa. Según la biografía, Adriano, mientras recorría Asia, templa sui nominis consecrauit, "consagró templos a su nombre". A pesar del equívoco al que pueden conducir las traducciones modernas, el texto latino poseía un significado preciso, tanto desde el punto de vista religioso, como institucional y edilicio. La consecratio implicaba la puesta en servicio del edificio, o el conjunto de edificios y monumentos, que se habían levantado sobre el templum, es decir, sobre el espacio religiosamente inaugurado. ${ }^{35}$ Este espacio segregado y santificado, convertido por la mano del augur en res sancta, se dotaba de una realidad material que, gracias a la consecratio, devenía res sacra. ${ }^{36}$ Por lo tanto, es evidente que Adriano no pudo proceder, en ningún momento, a la consagración de su templo de Éfeso porque durante su última visita a la ciudad, en el año 131, únicamente había concedido el permiso para su construcción. Las obras del templo se prolongaron hasta el límite del reinado del emperador, si no más allá. La consecratio de aquel nuevo templo recayó, finalmente, en Diophante, quien había conseguido el permiso imperial para su construcción. El término latino de consecratio que aparece en la Historia Augusta encontró su traducción directa e inmediata en la palabra griega kaӨı́́ $\rho \omega \sigma \iota c ̧$ de la inscripción efesia. Este ritual fue oficiado y presidido, en Éfeso, por el sacerdote de culto imperial, el archiereus Clau-

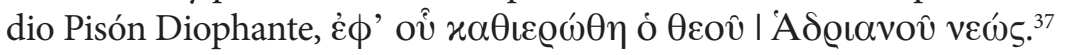

El resultado de esta primera pesquisa fundada en la comparación entre el texto de la Historia Augusta y las evidencias epigráficas disponibles para el proceso de concesión, construcción y consagración del nuevo templo imperial de Éfeso no es en modo alguno sorprendente. El relato histórico contenido en la biografía del emperador, incluso cuando mantiene una armazón cronológica, no estaba constreñido por criterios modernos de exactitud o, ni siquiera, por la antigua akríbeia. El autor, o los autores, tendían a concentrar acontecimientos en aquellos momentos de la narración en los que la asociación de ideas o la ordenación temática así lo aconsejaban. Esta técnica historiográfica, que dificultaba la ubicación temporal y espacial de cada una de las acciones imperiales aunque facilitaba tanto la narración como la lectura, ya había sido reconocida en otros pasajes de la obra. Sin duda, la reunión de todas las reformas militares de Adriano en el momento del primer viaje a Germania, en el

35. Kvium, 2011, pp. 63-90.

36. Linderski, 1986, pp. 2240-2250.

37. IvE 428. 
año 122 , respondía a este proceder, sencillo y eficaz. ${ }^{38} \mathrm{Y}$ ahora, como hemos tenido ocasión de ver, se repite también, aunque de manera más breve, en la evocación del viaje por Asia de los años 129 al 131, camino de ida y vuelta a Egipto.

Así, desvelados algunos de los procedimientos narrativos de la Historia Augusta y aclarado hasta donde se puede el proceso histórico de fundación y consagración del templo de Adriano en Éfeso, es el momento de volver a Atenas.

\section{El templo de Zeus Olimpio}

Según el biógrafo, cuando Adriano llegó a Atenas para su segunda estancia en la ciudad, en el año 128-129, opera quae apud Athenienses coeperat dedicauit, ut Iouis Olympii aedem et aram sibi, "dedicó las obras que había empezado en Atenas, como el templo de Júpiter Olimpio y un altar para él mismo". Sin embargo, una evidencia independiente, una inscripción proveniente de Epidauro, pone en duda lo dicho en el pasaje de la biografía.

La referida inscripción del templo de Asclepio en Epidauro establece la relación cronológica entre algunos de los acontecimientos más importantes del reinado de Adriano en la Hélade: la consagración del templo de Zeus Olimpio, la fundación del Panhelenion y la era adrianea, aquella que se inició con la primera visita imperial a Grecia. ${ }^{39}$ Las primeras cinco líneas del epígrafe dicen así:

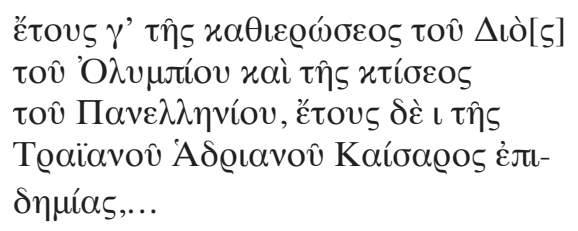

Al tercer año de la consagración del Zeus Olimpio y de la fundación del Panhellenion, a los diez años de la visita de Trajano Adriano César...

El elemento clave para la interpretación cronológica del epígrafe es la determinación de la fecha de la era de Adriano en Grecia, era que parte de su primera visita. Fue mérito de Weber, Graindor y Follet fijar esta fecha: Adriano visitó la Hélade, por primera vez como emperador, en el otoño del año 124, dato posible gracias a otra inscripción que ubica esta primera visita adrianea en el año de su

38. HA, Hadr. 10, 2 - 11, 1. Fünding, 2000, pp. 253-273.

39. $I G I^{2} 1,384$. Oliver, 1970, pp. 119-120, $\mathrm{n}^{\circ} 38$, donde se resalta su valor cronológico. 
octava potestad tribunicia. ${ }^{40}$ Las cuentas son sencillas: los diez años se cumplirían en el año 134 y la consagración del templo de Zeus Olimpio se debería colocar en el año 131-132. La consecuencia es evidente: la negación del valor cronológico del pasaje de la Historia Augusta. Sencillamente, debería admitirse, como hemos visto que ocurría en el caso de Éfeso, que el biógrafo no se sintió obligado a mantener la exactitud temporal en la narración de los acontecimientos del reinado y prefirió comprimir los acontecimientos de varios años en un solo punto de su narración. De esta forma le daríamos prioridad en la fijación de la cronología de algunas acciones del emperador en Oriente a las evidencias epigráficas, libres como están de los condicionantes de la historiografía antigua.

No obstante, desde hace mucho tiempo, en verdad, a partir de la obra de Weber, ${ }^{41}$ ha prevalecido una interpretación conciliadora con la que se pretende concertar la noticia de la Historia Augusta con el epígrafe de Epidauro. Esta conciliación se habría conseguido atribuyendo acciones distintas a cada una de las fuentes aparentemente contradictorias y, en consecuencia, fechas distintas para su realización. Cuando se lee todo el pasaje completo, tal y como aparece recogido al principio de este trabajo, podría dar la impresión de que la Historia Augusta pretendía hacer una distinción sutil que, quizás, tuviera un significado histórico. Mientras que para los templos asiáticos el verbo utilizado es consecrauit, el término empleado para referirse al templo de Zeus Olimpio es dedicauit. Esta diferencia en los términos le permitió a Weber pensar que en el año 128 Adriano habría "dedicado" la aedem, cuya construcción ya había terminado, mientras que en el 131-132, durante su última estancia en Atenas y a la vuelta de su viaje por Oriente, el emperador habría procedido a la auténtica "consagración" de todo el recinto sacro, el témenos de Zeus Olimpio, tal y como afirma la inscripción de Epidauro.

La hipótesis de dos acciones distintas, una en el 128 cuando todavía no estaban terminadas las labores edilicias y urbanísticas del conjunto, y otra en el 131-132 destinada a cerrar un ciclo constructivo y religioso abierto por Pisístrato, ha calado profundamente en la historiografía moderna a pesar de que, a veces, ha generado notable confusión. Paradigmático, y de extraordinario valor por la influencia de la magistral obra, es lo que Graindor escribió sobre el asunto: ${ }^{42}$

40. IG IV $I^{2}, 1,606$ (=SEG 842 , n. 3). Weber, 1907, pp. 158-160, 182-3; Graindor, 1934, pp. 1-6; Follet, 1976, pp. 108-113.

41. Weber, 1907, pp. 205-210.

42. Graindor, 1934, p. 42. 
"Mais comment concilier ce texte avec tous ceux qui nous forcent à placer l' inauguration du temple en 132? En supposant, comme l'a fait Weber, qu'en 129 Hadrien se borne à consacrer la cella de l'Olympieion et l'autel qui y était réservé à son propre culte".

Esta interpretación, seductora porque evita el conflicto entre las fuentes, se vuelve inaceptable por la confusión de términos y rituales. "Inauguratio", "dedicatio" y "consecratio" se mezclan en el texto francés sin ningún respeto a sus significados en el mundo antiguo y a sus fuentes.

En el proceso de creación de un templo romano dos son los momentos de significado religioso, legal y edilicio. El primero es la inauguratio ${ }^{43}$ en el que, consultando los auspicios, se definía, se segregaba, un espacio celeste y terrestre que quedaba constituido así en templum. Desde luego, este acto era tan innecesario como, quizás, inviable en suelo ateniense; innecesario porque el santuario de Zeus Olimpio ya era, para los atenienses, un auténtico templo, aunque inacabado, desde tiempos de los tiranos, ${ }^{44}$ si no antes; inviable, porque la inauguratio, el ritual de los augures romanos, sólo podía realizarse sobre suelo romano. Esta era una condición que no cumplía el territorio ateniense, ciudad libre organizada como una polis griega.

Por otra parte, y siguiendo siempre la ley y el uso romanos, sobre aquel espacio segregado por los augures - templum - se podía, o no, construir un edificio, aedes, para que sirviera de santuario, además de levantar el altar - ara - o los altares que se consideraran necesarios para la realización del culto. Sólo cuando la obra estaba terminada y se iba a poner en servicio el recinto construido, se procedía a la consecratio ${ }^{45}$ que, como hemos visto, en Éfeso se había traducido al griego por $x \alpha \theta$ เé $\mathrm{Q} \omega \sigma \iota \varsigma$. Únicamente podría resultar legítimo evocar este acto de consecratio del templo por medio del término castellano de "inauguración" cuando este se utilice en su acepción de "celebrar con alguna ceremonia el estreno de un edificio o monumento de pública utilidad". ${ }^{46}$ Así es porque en castellano, como en otras lenguas modernas, la inauguración ha perdido toda conexión con el ritual romano de la inauguratio.

Es cierto, por otra parte, que los términos latinos dedicatio y consecratio podían encerrar alguna diferencia jurídica y religiosa. La dedicatio parece haber tenido un valor jurídico más profundo en tanto que sólo podía ser realizada por autoridades legalmente reconocidas. La consecratio, en cambio, caía en el ámbito

43. Kvium, 2011, pp. 63-90.

44. La sacralidad del templo de Zeus Olimpio era indiscutible para los atenienses y se remontaba a una época anterior, incluso, a la fundación de la ciudad: Wycherley, 1964, pp. 161-179.

45. Linderski, 1986, pp. 2240-2250.

46. DRAE, s.v. "Inaugurar", p. 4. 
de la acción privada y particular, ajena a la vida pública. No obstante, ambos términos acabaron confundiéndose con el devenir de los años, especialmente cuando estaban referidos a templos que, aunque hubiesen sido levantados por particulares, adquirían un cierto cariz público en tanto que realidad sagrada o religiosa ${ }^{47} \mathrm{Y}$ así, aunque el acto que jurídicamente les pudiera corresponderle fuese la dedicatio, los templos podían ser objeto también de una consecratio, que se cargaba entonces de un nuevo formalismo y rito. Es precisamente esta paulatina confusión en el mundo

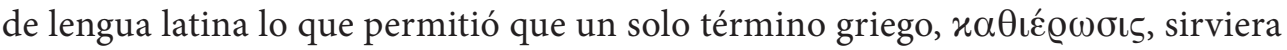
para expresar ambos rituales, cuya diferenciación legal no era percibida desde la óptica griega. Esto fue así, en parte, porque en el mundo griego no existía la diferencia jurídica que separaba ambos términos latinos; en parte porque esa diferencia se estaba diluyendo también en el mundo latino. Es sin duda esta confusión, plenamente asentada ya en tiempos del Imperio, la que permitió que un mismo término griego, $x \alpha \theta \iota \varepsilon ́ \varrho \omega \sigma \iota \varsigma$, presente tanto en la inscripción de Epidauro, para el templo de Zeus Olimpio, como en la inscripción de Éfeso, para el templo de culto imperial, fuera traducida al latín en la Historia Augusta o, mejor aún, en su fuente, por dos términos latinos que eran concebidos, ya en el siglo IV, como equivalentes: dedicatio y consecratio. Y así, la diferencia de términos que podemos leer hoy en el pasaje de la Historia Augusta sólo habría respondido a una voluntad de estilo, a una cierta necesidad estilística de variación literaria. ${ }^{48}$

Las conclusiones de todo lo dicho pueden resumirse de la siguiente manera: en la Historia Augusta, dedicatio y consecratio tienen el mismo valor y ambos términos

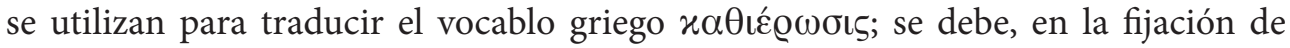
la cronología, conceder prioridad probatoria a las inscripciones griegas de Éfeso y Epidauro, lo que implica que el año 128-129 no fue testigo ni de la consagración del templo de Zeus Olimpio ni de la del nuevo templo de culto imperial en Éfeso; que la Historia Augusta, como en otros lugares, sólo mantiene la secuencia cronológica de manera general, sin exactitud en la ubicación de acontecimientos concretos. De esta forma, la hipótesis de Weber, generalmente aceptada, de una doble ceremonia en el templo de Zeus Olimpio de Atenas, una primera en la que se habría procedido a la dedicación parcial de las obra en el 128-129 y otra más tardía, en el 131-132, en el que se consagró el templo, queda sin fundamentos. En lugar de duplicar acontecimientos es más sencillo, económico y coherente admitir que la Historia Augusta no tuvo nunca la voluntad de ser precisa en la fijación temporal de los acontecimientos.

47. Mrozek, 2004, pp. 119-134.

48. Mrozek, 2004, pp. 125-126. 
El templo de Zeus Olimpio se habría terminado, consagrado y abierto al culto en el año 131-132.

\section{Adriano Olimpio}

Todas las evidencias discutidas hasta ahora conducen a esa misma conclusión: el año 131-132. No obstante parece existir un argumento contrario a esta tesis, un argumento que podría sostener la fecha temprana del 128-129: el título de Olimpio que Adriano ostenta en algunos epígrafes griegos.

Como parte de la argumentación a favor de su hipótesis de la doble ceremonia en el Olimpieion, ${ }^{49}$ Weber incluyó el título de Olimpio. Muchas ciudades griegas y algunas ligas le atribuyeron este epíteto al emperador durante los últimos años de su reinado. Para el autor alemán, Adriano habría comenzado a utilizar el título de Olimpio en el año 129 como consecuencia de la dedicatoria del templo de Zeus Olimpio en Atenas. Para sostener su argumento Weber ofrecía una inscripción de Éfeso ( $I V E$ 274) que, siguiendo la edición de Dittenberger, se habría de datar en la decimotercera potestad tribunicia (128-129). En ella Adriano habría sido llamado, por primera vez, Olimpio.

La inscripción ha tenido una vida difícil. Perdido el monumento, su texto sólo ha llegado hasta nosotros a través de la copia que del epígrafe hizo Ciriaco de Ancona, en la primera mitad del s. XV. De los manuscritos de Ciriaco salió a la luz y se convirtió en parte de las evidencias históricas sobre el reinado de Adriano en el año 1877, cuando O. Riemann transcribió, para el volumen primero del Bulletin de Correspondance Hellenique, los epígrafes de un manuscrito florentino. ${ }^{50} \mathrm{El}$ texto fue leído por Dittenberger e incluido en la segunda edición de su Syllogue tras haber propuesto algunas correcciones y suplementos. Allí lo encontró Weber y de allí se incorporó a la tercera edición del SIG y, más tarde, a la serie de Inschriften griechischer Städte aus Kleinasien ${ }^{51}$ Así es como puede leerse hoy en las ediciones canónicas:

49. Sobre las variaciones en el nombre del templo, Olympieion u Olympion: Wycherley, 1964, pp. 161-162.

50. Riemann, 1877, p. 291, n 78.

51. $S I G^{2}$ 389; Weber, 1907, p. 212; $S I G^{3}, 839 ; I v E 274$.

ARYS, 16, 2018 [207-238] ISSN 1575-166x 


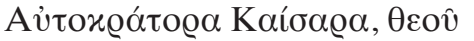

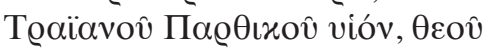

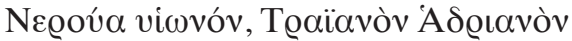

$\Sigma \varepsilon \beta \alpha \sigma \tau o ̀ v ~ x \alpha \iota ̀ ~ ' O \lambda v \mu \pi เ о v, ~ \delta \eta \mu \alpha \varrho$

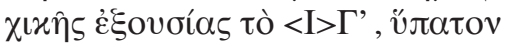

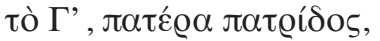

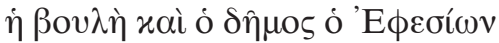

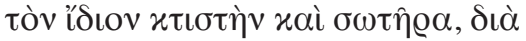

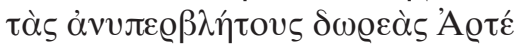

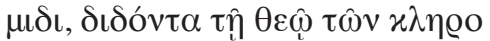

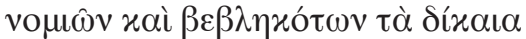

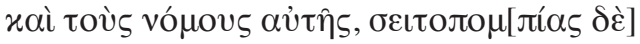

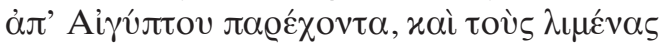

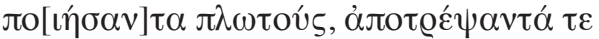

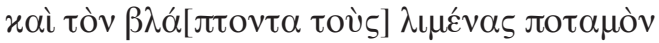

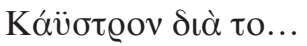

Al emperador César Trajano Adriano Augusto también Olimpio, hijo del dios Trajano Pártico, nieto del dios Nerva, en su decimo tercera ( ${ }_{i}$ ? $)$ potestad tribunicia, cónsul tres veces, padre de la patria, el consejo y el pueblo de Éfeso [levantaron esta estatua de su] particular fundador y salvador, gracias a sus insuperables dones a Artemisa, puesto que le dio a la diosa los derechos sobre los herederos y los ¿beblekoton? y las leyes de esta, porque le proporcionó el suministro de trigo desde Egipto, porque hizo navegables sus puertos ya que el río Caistro había colmatado y obstaculizado los puertos...

El manuscrito presentaba numerosas incertidumbres que, en parte, ya fueron corregidas por Riemann o resueltas, después, por la autoridad de Dittenberger. Así, la

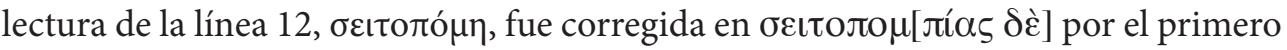
y aceptada por el segundo. A Riemann también se deben los suplementos de las líneas 14 y 15, quien indicó que las sílabas que faltaban habían sido dejadas en blanco en el manuscrito. Riemann creyó, además, que el texto de las líneas 11 y 12 estaba alterado, pues desconocía el valor de $\beta \varepsilon \beta \lambda \eta x o ́ \tau \omega v$, lo que también Dittenberger ignoraba y se sigue ignorando. Estaba inclinado a pensar que, un poco más adelante, debería leerse

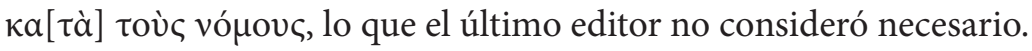

Entre la edición de Riemann y la de Dittenberger, no obstante, hay una gran diferencia. El primero transcribió las líneas 4 y 5 literalmente del manuscrito, líneas que

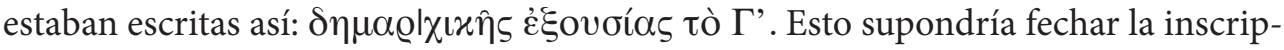
ción en el año 118-119, año de la tercera potestad tribunicia. Fue Dittenberger quien se dio cuenta del error en la transmisión del número de la potestad, que no encajaba con el título imperial de Padre de la Patria, otorgado y aceptado en el año 128 y que 
aparece en la línea sexta. Por eso propuso corregirlo en $\tau$ ò $<\mathrm{I}>\Gamma$ ', la decimotercera potestad tribunicia, lo que equivaldría al año 128-129. Esta enmienda era sencilla y efectiva: sólo había que añadir una letra, una cifra, al texto corrupto. ${ }^{52}$ Corregida la fecha del epígrafe, se pudo datar la concesión del título de Olimpio. El epígrafe de Éfeso se convirtió en la prueba que Weber necesitaba para sostener su hipótesis de la concesión del título de Olimpio en el año 128-129, como consecuencia de la dedicación del edificio del santuario ateniense. Pero ninguna otra inscripción, ni entonces ni ahora, aporta esa fecha de forma segura para el título divino, que queda así dependiente de una inscripción enmendada. Se hace necesario repensar el asunto.

L. Perret, en su clásico estudio sobre la titulatura imperial de Adriano, se sumó a las tesis de Weber y Dittenberger: el título de Olimpio dataría del año 128-129.53 Para apuntalar la hipótesis ofreció cuatro bloques de testimonios, el primero, constituido por el ya citado epígrafe de Éfeso, los demás, por inscripciones de Atenas y Phasélide. ${ }^{54}$ Desgraciadamente, el testimonio ateniense debe descartarse porque está vinculado a las Olimpiadas de Atenas, fiesta cuya datación depende a su vez, de la fecha de la dedicación del templo de Zeus Olimpio, y no a la inversa. ${ }^{55}$ Los otros epígrafes provienen de la ciudad de Phasélide. En ellos el emperador lleva el nombre de Olimpio y el título de Padre de la Patria, mientras que no aparece la segunda aclamación imperial. Careciendo de una mayor precisión, esto sitúa a los epígrafes entre los años 128 y 135. Pero como ambos monumentos fueron levantados para conmemorar el desembarco de Adriano en aquellas tierras, posiblemente, a su regreso de Egipto, habría que situarlos en el año 131, es decir, antes de la última estancia en Atenas y de la consagración del templo de Zeus Olimpio. Por esta razón Perret consideró que podían apoyar la idea de una concesión del título en fecha anterior, posiblemente

52. La aceptación de la corrección de Dittenberger ha sido unánime. En IVE 274, señalada la adición $\tau$ ò $\left\langle\mathrm{I}>\Gamma^{\prime}\right.$ - no se hace referencia alguna ni a su autor ni a las implicaciones de la misma.

53. Perret, 1929, pp. 30-33.

54. Estas inscripciones, citadas en sus ediciones modernas de referencia, son, $I v E 274, I G \mathrm{II}^{2} 3303$, TAM II 1192, 1193. Estos dos últimos ya fueron citados antes, n. 22.

55. IG II ${ }^{2}$ 3303. El debate historiográfico es sencillo aunque la cuestión histórica irresoluble, por ahora. Todos los estudiosos que han tratado el tema consideran que el inicio de la celebración de las Olimpiadas en Atenas estuvo vinculado al templo de Zeus Olimpio. Para Weber, 1907, p. 210, la primera Olimpiada habría tenido lugar en el año 128-129, al hilo de su pretendida ceremonia de dedicación del templo. Graindor, 1934, p. 42, en cambio, creyó que debería situarse en el año 132, con la "inauguración" del templo. Follet, 1976, pp. 345-346, se alineó con la tesis de Weber. Sin embargo, y como bien se puede observar, el argumento es circular, haciéndose depender mutuamente, y sin ninguna evidencia externa, la fecha de templo y la de las Olimpiadas de Atenas. Ha de considerarse, sin embargo, que el retraso de la fecha de celebración de los primeros juegos Panhelénicos en Atenas, del año 132 al 137, Wörrle, 1992, pp. 337-349, favorece la fecha de 132 como la de inicio de los Olimpiadas atenienses.

ARYS, 16, 2018 [207-238] ISSN 1575-166X 
en 128-129. No obstante, es necesario admitir que estos monumentos tampoco son pruebas concluyentes para apoyar la datación en el año 128-129, aunque deban ubicarse, como así lo creo yo también, en el año 131.

Para explicar mis reticencias, se hace necesario traer a colación una reflexión general sobre el valor y el procedimiento de concesión de los cognomina divinos a Adriano.

\section{LOS NOMbres divinos de Adriano: Olimpio}

En un turbulento inicio del reinado, se atribuyeron al nuevo emperador todos los cognomina honoríficos de su predecesor, Trajano. Las monedas de la ceca imperial no dudaron en proclamar al nuevo emperador como Dácico, Pártico y Óptimo, además de Padre de la Patria, aun cuando no tenemos noticias de cuándo y cómo se le otorgaron tales honores. La única explicación posible, a mi entender, es que estas series numismáticas habían sido acuñadas como parte de un proceso sucesorio ya planificado, un proceso que habría necesitado de la postrera presencia de Trajano en Roma para proceder a la adopción de Adriano y a su designación como César, primero, y como emperador, después. Sólo la inoportuna muerte del emperador en Selino habría impedido proceder a una ordenada sucesión. No obstante, el desbaratamiento de los planes no evitó que se lanzaran las monedas ya preparadas para dar a conocer el nombramiento del sucesor y su llegada al trono. Así se hizo a pesar de que no se había llegado a producir el acto romano de la adopción pública y de la transferencia de poderes y títulos. ${ }^{56}$

La reacción del nuevo emperador al caos creado por la discrepancia entre la propaganda pública, los actos oficiales y la enemiga acérrima de un grupo de senadores contrarios a su sucesión, fue la renuncia total a los títulos y honores paternos y, en verdad, a cualquier título y honor expresado en forma de apelación o cognomen. En una famosa carta al senado, de la que tenemos noticias tanto en Casio Dion como en la Historia Augusta, Adriano renunció formalmente a aquella herencia honorífica. ${ }^{57}$ Esta reacción permitió al emperador, de hecho, iniciar una vía de sentido contrario, simplificando sus nombres imperiales hasta dejarlos en el límpido Hadrianus Augustus, divisa de su reinado. Fue sólo una década más tarde, en el 128, que el emperador estuvo dispuesto a aceptar el título de Pater Patriae.

Pero entre el título honorífico de Pater Patriae y el cognomen Olimpius con el que se le honraba en Grecia hay una diferencia importante. La concesión al empera-

56. Cortés Copete, 2014, pp. 187-208.

57. Cass. Dio, LXIX 2, 2; HA, Hadr. 6, 1-4. Cf. Perret, 1929, pp. 26-30. 
dor del título de Pater Patriae fue, como bien se sabe, un acto formal del Senado y del Pueblo de Roma. Estos, al modo de lo ocurrido con Augusto, le ofrecieron al emperador aquel honor con el ruego de que lo aceptase. Aunque el rechazo imperial había sido posible en un primer momento, este sólo tuvo un carácter temporal y dilatorio. El título de Pater Patriae - así como los otros cognomina honoríficos vinculados a victorias y conquistas de pueblos extranjeros en el caso de otros emperadores - fue el resultado de un acto formal, con valor jurídico, conducido por el Senado legalmente constituido. ${ }^{58} \mathrm{La}$ consecuencia más visible de aquella decisión institucional fue la inclusión en la denominación oficial del emperador del título de Pater Patriae, que así comenzó a aparecer en monedas, correspondencia oficial e inscripciones honoríficas. Nada de esto podemos esperar en el caso del cognomen Olimpio.

Sin duda alguna, la contemplación en el año 128-129 del avance de los trabajos del templo de Zeus en Atenas tuvo que producir una cierta excitación política y religiosa en las ciudades griegas, especialmente en Atenas. El templo iniciado en el s. VI a.C. parecía haber iniciado su camino de perfección. Se había tenido que esperar hasta el reinado de aquel emperador extraño, filoheleno y volcado a las provincias, para encontrar la voluntad y los recursos necesarios para corregir aquella muestra de desidia histórica. Es ese ambiente de lealtad y fervor creciente el que explica que al emperador se le diera el nombre de Olimpio, quizás porque había conseguido vencer al tiempo, ${ }^{59}$ victoria sólo reservada a los más poderosos de los dioses, quizás porque podía reconocerse en su fértil poder una muestra del propio poder del padre de los dioses. ${ }^{60}$

Fuera como fuese, esa efervescencia política y religiosa, que se plasmó en la aclamación del emperador como Olimpio, no supuso la decisión de un órgano legamente constituido y reconocido, con poder para otorgarle a Adriano el cognomen divino. No existía, todavía, una Liga de todas la ciudades griegas que pudiera haber tomado esta decisión; ${ }^{61}$ no parece, tampoco, que la tomaran los koina preexistentes ni que, en el caso de que así lo hubiesen hecho, las decisiones de las respectivas ligas se tomaran de forma coordinada y concertada. Más bien, da la impresión de que fueron muchas decisiones de muchas ciudades que, en un breve periodo de tiempo,

58. Hammond, 1959, pp. 58-91. El Senado como autor de los títulos, honores y triunfos de los emperadores: Talbert, 1984, pp. 354-371.

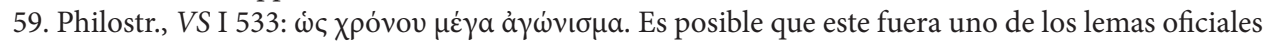
de la consagración del templo, cuyo discurso pronunció Polemón.

60. Cortés Copete, 2017a.

61. La fecha de constitución del Panhelenion es 131-132, coincidiendo con la consagración del templo del Zeus Olimpio: IG IV ${ }^{2}$ 1, 384. Spawforth y Walker, 1985, p. 78; Gordillo, 2012, pp. 37-43. 
estuvieron dispuestas a reconocer el carácter olímpico del emperador por medio de actos políticos independientes. No podemos saber qué ciudad tomó la iniciativa ni cuántas iniciativas concomitantes hubo. Tampoco conocemos la forma de cada una de aquellas iniciativas que tuvieron en común la proclamación de la divinidad, del poder divino, del carácter divino o de cualquier otro aspecto vinculado a la relación del emperador con los dioses, que se expresó con el nombre de Olimpio. Pero sí podemos estar seguros de que no hubo nada parecido a una decisión del Senado romano que proporcionara la legalidad, la formalidad y el universal reconocimiento al nuevo sobrenombre. ${ }^{62}$

Algunos indicios permiten imaginar, no obstante, cómo ocurrió realmente: muchas ciudades, ante el estímulo de las obras del templo, y siguiendo una iniciativa posiblemente ateniense, la primera y la más beneficiada de todas las ciudades, a la vista de los inagotables dones que repartió el emperador en los nuevos viaje por Asia del año 129 y del 130-131, a su regreso de Egipto, y ante los permisos para levantar nuevos templos consagrados a su propia persona, sintieron la necesidad de proclamar la vertiente divina del emperador, su cara olímpica.

Quizás uno de los monumentos más relevantes para comprender este proceso sea la estela que contiene la carta de Adriano a Atenas por la que otorga a la ciudad un nuevo gimnasio o, al menos, el embellecimiento de uno preexistente. ${ }^{63}$ La estela, decorada, en su parte superior, con un frontón triangular en cuyo centro se ha esculpido en relieve un escudo redondo, recoge, naturalmente, los títulos oficiales del emperador como remitente de la carta: Augusto, Pontífice Máximo, decimosexta potestad tribunicia, tres veces cónsul. No obstante, los atenienses decidieron dedicar al emperador la estela que iban a erigir con el texto de la carta y por eso, en el centro del escudo redondo situado en el frontón, grabaron su nueva advocación divina, en caso acusativo como acto de dedicación: O $\ \Upsilon$ M $I I O N$. De esta forma se hizo evidente que la concesión del nombre divino era un acto de la ciudad de Atenas, distinto de sus títulos oficiales romanos, pero oficial en tanto que cívico. Otras ciudades del Oriente estaban haciendo cosas semejantes. ${ }^{64}$ Sin embargo, no todas lo hicieron de la misma manera, señal de la inexistencia de esa decisión universal que nunca estuvo detrás del

62. El propio Graindor, 1922, pp. 130-131, reconoció esta circunstancia, aunque sin comprenderla bien, "Le titre d'Olympios, appliqué à Hadrien, es déjà officiel en 128-129, mais pas à Athènes, semblet-il".

63. IG $\mathrm{II}^{2}$ 1102. Editio princeps con fotografía, Sauciuc, 1912, pp. 183-189. El texto, en cualquier caso, no puede interpretarse sin las lecturas mejoradas de Graindor, 1914, pp. 392-396.

64. Un procedimiento similar es el que utilizó Mileto para publicar otra carta de Adriano. Allí, sin embargo, no se le otorgó el nombre de Olimpio, sino que se le proclamaba Prophetes: Oliver, 1989, nº 87. 
título de Olimpio y de la fecha del 128-129. De nuevo volveremos a Éfeso, que nos puede servir de testigo de la diversidad de decisiones tomadas por las ciudades.

En la ya citada inscripción que recuerda el embellecimiento de las estoas del gimnasio del puerto de Éfeso, ${ }^{65}$ fechada por el procónsul en el año 130-131, el emperador es proclamado $\Delta \iota \grave{~ ' O} \lambda v \mu \pi i ́ \omega[\iota]$, fórmula diferente a la que triunfó en Atenas, ciudad en la que no aparece el nombre del dios sino sólo su epíteto olímpico. No es exclusiva de la inscripción de la estoa la proclamación de Adriano como Zeus Olimpio. Una serie de altares efesios, todos ellos en dativo y con un texto similar,

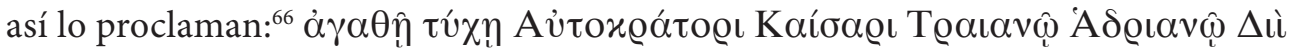
'O $\lambda v \mu \pi i \omega_{1}$. Sin duda, no podemos magnificar el significado de esta diferencia, pero tampoco podemos obviarla cuando la fórmula de Zeus Olimpio se multiplica por las ciudades asiáticas ${ }^{67}$ y no parece que se encuentre fuera de aquella provincia. Quizás la propuesta de explicación más sencilla, porque es capaz de aglutinar todos los aspectos que han ido siendo señalados, es que se tratase de una fórmula nacida en las ciudades de Asia para plasmar es idea de la naturaleza olímpica del emperador que se estaba revelando o desvelando en sus obras.$^{68}$ Esta fórmula, concomitante con el espíritu de lo que se hacía en Atenas, no fue idéntica a la ateniense por las incertidumbres teológicas que planteaban las distintas concepciones de la divinidad del emperador. Y así, mientras que en Atenas se optó por la directa advocación de Olimpio, en algunas ciudades de Asia, en un primer momento, se inclinaron por su asimilación a Zeus Olimpio.

No obstante, la presencia del nombre de Zeus entre los títulos imperiales acabó por desaparecer también de las ciudades de Asia, donde finalmente prevaleció el cognomen Olimpio sin mención alguna a Zeus, tal y como ocurría en otros lugares del mundo griego. Quizás tengamos una pista de cuándo y cómo se produjo esa normalización. En el año 132, para la consagración del templo de Zeus Olimpio, muchas ciudades griegas mandaron diputaciones y representantes a la ceremonia. Fueron estas legaciones las encargadas de levantar algunos monumentos dedicados al emperador, ya bien en la forma de estatuas (y con el nombre del emperador en acusativo), ya como altares (con el nombre en dativo). ${ }^{69}$ Entre todas las estatuas levantadas al empe-

65. IvE, 430. Vide supra, n. 20.

66. IvE, 267-271 a.

67. Algunos ejemplos: Mitilene: IG IV 85; Samos: IGR IV 986; Tiatira: IGR IV 1196; Metropoli: IGR

IV 1594; Tiris: IGR IV 1661. Es evidente que hace falta un estudio sobre el particular.

68. El proceso de construcción teológica de la divinidad imperial, Cortés Copete, 2017b, pp. 112-136.

69. Basas de estatuas de Adriano, $I G \mathrm{II}^{2} 3288-3322$. Altares de Adriano, $I G \mathrm{II}^{2}$ 3324-3381. Benjamin, 1963 , pp. 57-86. 
rador, se conserva la basa de la estatua erigida por Éfeso. Desgraciadamente el texto está mutilado pero sus restos son suficientemente explícitos para mis propósitos: ${ }^{70}$

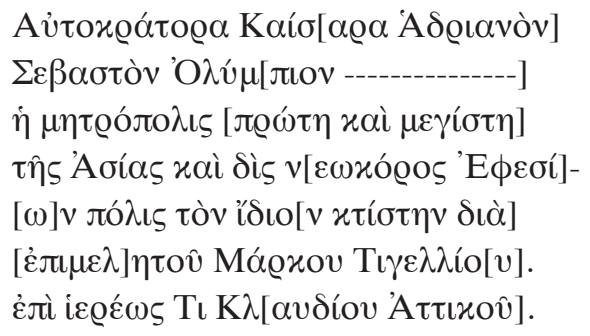

Al emperador César Adriano Augusto Olimpio [- - - ], la primera metrópolis y más grande de Asia, la ciudad de los efesios, dos veces neokoros, a su particular fundador, gracias a su encargado Marco Tigelio, bajo el sacerdocio de Tiberio Claudio Ático.

Aquí ya, y contra la primera tradición efesia, la advocación de Olimpio aparece normalizada, olvidándose la denominación de Zeus Olimpio. La reunión de Atenas en el año 131-132 había producido, a mi entender, la unificación en todo el mundo griego de la denominación del emperador, que en los años previos había mostrado una cierta tendencia a la variedad, incluyendo o no el nombre del padre de los dioses. Fue a partir de esa fecha que comenzó a existir la primera federación auténticamente panhelénica de la Antigüedad por lo que, por primera vez en la Historia, fue posible una decisión común de los griegos. Y así, en monumentos de Éfeso posteriores a la consagración del templo de Atenas tampoco aparece ya Adriano como Zeus Olimpio, sino sólo acompañado con el cognomen de Olimpio. ${ }^{71}$

Cuando se reúnen en una misma construcción los aspectos institucionales (la ausencia de un único organismo que pudiera otorgar el título de Olimpio de manera oficial hasta la fundación del Panhelenion), las diversidad teológica (las distintas versiones y visiones de la divinidad del emperador), las evidencias epigráficas (leídas en serie y con especial atención a sus indicaciones cronológicas), parece que resulta clara la idea de que los griegos, asombrados por la gesta de la conclusión del templo de Zeus Olimpio, ya desde el 128, comenzaron a asimilar al emperador con el padre de

70. IG II ${ }^{2}$ 3297. Benjamin, 1963, p. 72. El hueco de la segunda línea se ha completado en $I G \mathrm{II}^{2} 3297$

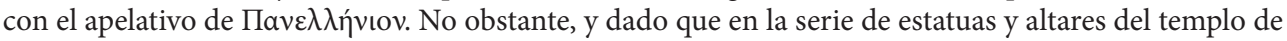
Zeus Olimpio este epíteto está ausente, sería más prudente pensar en otras restituciones, siguiendo los ejemplos de $I G \mathrm{II}^{2} 3291,3293,3302,3306$, archagetes, patera patridos, oikisten.

71. IvE 272-273. 
los dioses, llamándolo Zeus Olimpio o simplemente Olimpio. El proceso de homogeneización de la aclamación sólo se produjo en un segundo momento, coincidente con la consagración del templo en el año 131-132. Reunidas en Atenas las embajadas de las innumerables ciudades griegas convocadas, todas, incluso aquellas que como Éfeso había preferido una fórmula más propia de las monarquías helenísticas, adoptaron la denominación de Olimpio. Dejaron testimonio de ello en las inúmeras basas y altares que, con uniformidad sorprendente y poco valorada, levantaron al unísono en el témenos del templo. Podría dar la impresión de que eran el resultado de una decisión previa, aun cuando en verdad no eran sino consecuencia de un diálogo que fue capaz de generar un singular consenso entre los súbditos de diversas provincias.

\section{Conclusión: Adriano, el templo de Zeus Olimpio y la INTEGRACIÓN DEL IMPERIO}

De todo este largo viaje entre Atenas y Asia siguiendo al emperador, del estudio de algunos de los acontecimientos que tuvieron lugar en Oriente durante la última década de reinado de Adriano, de la comparación entre lo hecho en Éfeso y en la capital del Ática, se pueden obtener algunas conclusiones. En primer lugar, resulta evidente que $H A$ 13, 6 no posee un verdadero valor cronológico y que en aquellas pocas líneas se comprimieron acontecimientos que se extendieron a lo largo de más de quince años. De igual modo, la vieja tesis de Weber sobre una doble ceremonia en el templo de Zeus Olimpio en Atenas, una primera en el 128 y otra posterior y definitiva en el 132, ha quedado sin fundamento. La consagración del templo se realizó de una sola vez en el año 132, dando pie a la constitución del Panhelenion. Por otro lado, resulta claro que entre los años 128 y 132 se vivió en Oriente un clima de excitación religiosa y política provocado por los beneficios que Adriano estaba concediendo a tantas y tantas ciudades durante aquella última gira oriental. Ese clima de efervescencia religiosa se plasmó en el reconocimiento de la condición olímpica de Adriano. En un primer momento las ciudades buscaron modos particulares para decir aquello que estaba ocurriendo: algunas como Éfeso prefirieron la tradición helenística e identificaron al emperador con Zeus Olimpio; otras, como Atenas, optaron por atribuirle el cognomen de Olimpio en reconocimiento de la naturaleza divina del emperador que por sus obras se desvelaba. Finalmente, todas las ciudades aunaron sus expresiones y, a partir de la consagración del templo de Zeus, acordaron otorgar al emperador el sobrenombre de Olimpio.

La consagración del templo de Zeus Olimpio fue el acto central de aquel periodo. Inaugurado en el siglo VI a.C. por los tiranos de Atenas, el emperador Adriano presidió una ceremonia que tuvo lugar en el año 132 d.C., una ceremonia que en 


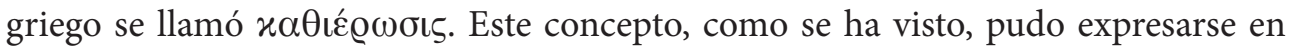
latín con dos palabras diferentes que se fueron haciendo sinónimas con el paso de los años: dedicatio y consecratio.

De aquella ceremonia tenemos un breve relato literario, tan valioso para comprender su desarrollo y valor como infrautilizado. En la biografía de Polemón que Filóstrato compuso para su serie de Vida de los sofistas se recuerda lo que ocurrió en Atenas en $132:^{72}$

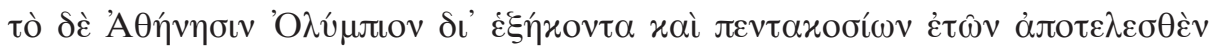

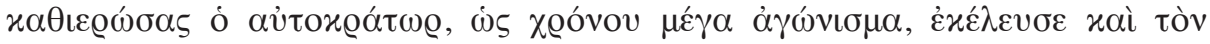

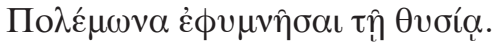

El emperador Adriano, quien, como en una grandiosa batalla contra el tiempo, consagró el Olimpio de Atenas, que se terminó tras quinientos sesenta años, ordenó asimismo a Polemón que cantara un himno en la ceremonia.

Es necesario detenerse en algunos detalles de este pasaje. La culminación de las obras del templo fue vista como una victoria sobre el tiempo, chronos, un triunfo que desvelaba o revelaba la cara divina del emperador y de su poder. Sólo los dioses, y no todos los dioses, podían corregir el destino. El propio Polemón se encargó de resaltar el componente divino de la acción imperial en el proemio a su himno de consagra-

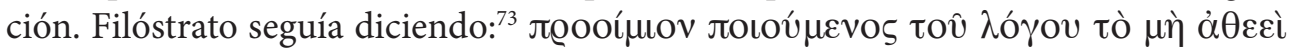

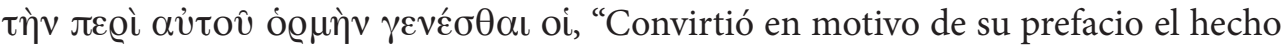
de que el estímulo inicial del discurso no le había venido a la mente sin ayuda de la divinidad". Esta divinidad no era otra que la que habitaba, de alguna forma, en Adriano,

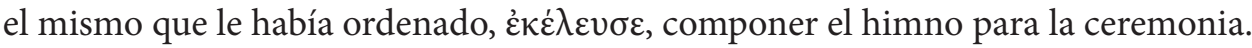

El segundo aspecto, aún más trascendental, es el protagonista de la ceremonia. La inscripción de Epidauro, al recordar la consagración del templo a través de un sustantivo nos hurtó la posibilidad de saber, de primera mano casi, quién consagró el templo. La Historia Augusta hizo sujeto de los dos verbos que emplea, dedicavit y consecravit, al emperador, aunque ya sabemos, al menos, que no fue Adriano quien consagró el templo de Éfeso. Y en cambio, Filóstrato aclara todas nuestras dudas para el caso de Atenas: $\varkappa \alpha \theta \iota \varepsilon \varrho \omega ́ \sigma \alpha \varsigma$ ò $\alpha u ̛ \tau o x \varrho \alpha ́ \tau \omega \varrho$, "consagrándolo el emperador". Para referirse a aquella ceremonia culmen Filóstrato podría haber utilizado otros términos griegos en lugar de kathierosis. De hecho, Pausanias, por ejemplo, prefirió

72. Philostr., VS I 533.

73. Philostr., VS I 533. 
utilizar otra palabra, quizás más común en la tradición religiosa griega: ${ }^{74}$ 'A $\delta$ pıvò

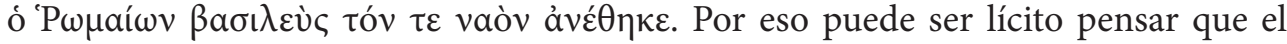
biógrafo de los sofistas prefirió recurrir en su texto al término que, como hemos visto en Epidauro, se utilizó oficialmente para describir aquella ceremonia en Atenas:

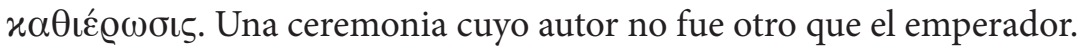

Este es un hecho de un extraordinario valor: en mi limitado conocimiento, este es el primer caso en el que un emperador consagraba un templo fuera del suelo romano ${ }^{75}$ entendido este como el suelo de la capital, de Italia, de una colonia o de un municipio; es decir, fuera de todo aquel suelo sobre el que el augur pudiera ejercer su autoridad y actividad. ${ }^{76}$ Adriano, al presidir y celebrar la consagración del templo de Zeus Olimpio en Atenas, estaba actuando como sacerdote supremo de Atenas - ciudad de la que era ciudadano y había sido arconte -, como Pontífice Máximo romano y, en una nueva condición, expansión de las dos anteriores: como sacerdote supremo del Imperio. Esto fue así porque, y no puede olvidarse, ni el suelo sobre el que se alzaba el magnífico templo de Zeus era romano, ni había sido inaugurado siguiendo alguna tradición y rito augural. La ciudad de Atenas era una ciudad jurídicamente libre y estaba constituida como una polis griega. Fue un paso gigantesco en el proceso de integración del Imperio el que Adriano dio con aquel acto de consagración del templo de Zeus Olimpio.

Apenas veinte años antes, el concienzudo gobernador del Ponto-Bitinia, Plinio el Joven, había planteado a Trajano una cuestión sobre un asunto que puede relacionarse con el que nos ocupa. ${ }^{77}$ Los habitantes de Nicomedia estaban empeñados en las obras necesarias para añadir un nuevo foro al antiguo. En el diseño del nuevo foro el viejo templo de la Magna Mater se iba a ver afectado. Se presentaban dos opciones de actuación: o se reconstruía el templo sobre el mismo lugar pero a una cota más alta o se trasladaba de ubicación. La condición de espacio sagrado del viejo templo inquietaba al gobernador quien, como escribe a Trajano, "había comprendido que las tradiciones de la consagración de los templos son aquí diferentes a la que existen

74. Paus., I 18, 5.

75. Quizás podría pensarse en el altar de Lugdunum como un precedente pero, además de que allí no está clara la participación de Druso en su dedicación, sólo posible si se consagró el altar en el 12 a.C. y no en el 10 a.C. como sostiene Suetonio, Clau. 2, 1, el altar fue concebido como una institución para los peregrinos, al modo del templo de Roma y Augusto en Pérgamo. Fishwick, 1987, pp. 102-137; Fishwick, 2002, pp. 9-19. Era evidente que aquel suelo de Lugdunum no era auténtico suelo religioso desde una perspectiva legal y ritual romana y que, por lo tanto, "the Lugdunum cult was not, of course, one of the cults of the Roman people", Rich, 1993, p. 199.

76. Catalano, 1978, pp. 491-505.

77. Plin., Ep. X 49-50. Ando, 2015, Chap. I. 
entre nosotros", cognoui alium hic, alium apud nos esse morem dedicationis. Plinio estaba preocupado ante la posibilidad de que la realización de aquella obra, sencilla técnicamente, acabara convirtiéndolo en sacrílego por no haber respetado las normas locales sobre la sacralidad de los espacios religiosos. La respuesta de Trajano es clara y refleja, con toda nitidez, la diferencia jurídica y religiosa que existía entre el suelo de las ciudades griegas y el suelo romano, así como la voluntad de Trajano de conservar aquella diferencia:

Potes, sine sollicitudine religionis, si loci positio uidetur hoc desiderare, aedem Matris Deum transferre in eam quae est accommodatior: nec te moueat quod lex dedicationis nulla reperitur, cum solum peregrinae ciuitatis capax no sit dedicationis, que fit nostro iure.

Puedes, sin ningún temor a cometer sacrilegio, y si el emplazamiento del lugar parece que así lo exige, trasladar el templo de la Madre de los Dioses a otro lugar que sea más adecuado. Y que no te preocupe el hecho de que no se encuentre ninguna reglamentación sobre su consagración, pues el suelo de una ciudad extranjera no es susceptible de una dedicación como la que se hace según nuestra ley.

Para Trajano, el suelo de una ciudad peregrina no era suelo auténticamente religioso $^{78}$ por lo que, se hiciera lo que se hiciera, y se hiciera como se hiciera, en los templos cívicos, no había ningún temor a cometer sacrilegio, sine sollicitudine religionis. Al no ser suelo romano no era suelo augural y, por lo tanto, no era auténtico suelo religioso. Esta era la misma opinión que, ya en la segunda mitad del siglo II, mantenía el jurista Gayo en sus instituciones: ${ }^{79}$ Sed in provinciali solo placet plerisque solum religiosum non fieri, "pero la mayoría están de acuerdo que en suelo provincial no se hace suelo religioso." No obstante, el jurista sabía que las consecuencias más radicales de esta afirmación habrían sido absolutamente contraproducentes, especialmente porque entre Trajano y Gayo había estado el fértil y, hasta cierto punto revolucionario, gobierno de Adriano con su giro a favor de las ciudades de las provincias. Por eso, un poco más adelante, el jurista matizaba:

Item quod in provinciis non ex auctoritate populi Romani consecratum est, proprie sacrum no est, tamen pro sacro habetur.

78. Catalano, 1978, pp. 495-497 y 499-502, para las actividades que sólo podían realizarse in agro Romano, siempre vinculadas con la inauguratio.

79. Gaius, Inst. II 5-7. 
Así pues, lo que en las provincias no está consagrado por la autoridad del pueblo romano propiamente no es sagrado, aunque se tenga por sagrado.

Dos son, de nuevo, las consideraciones. En primer lugar, la utilización de la ficción jurídica para salvar un vacío legal de imposible gestión: ${ }^{80}$ los templos de los provinciales, constituidos y consagrados según las costumbres locales, debían seguir siendo tratados "como si" fueran sagrados, pro sacro, con la intención de evitar un vacío en el reconocimiento legal que hubiese generado múltiples conflictos. Pero ahora se hace más interesante la primera circunstancia que recuerda Gayo y que, por otra parte, suele pasar desapercibida. Lo consagrado en las provincias por autoridad de Roma, ex auctoritate populi Romani, a diferencia de lo hecho por las autoridades locales, sí era auténticamente religioso. Quizás el primero y el más notable ejemplo de esta realidad fuera el templo de Zeus Olimpio en Atenas. Levantado sobre suelo de una ciudad libre en la provincia de Acaya, remontando su sacralidad a tiempos anteriores, incluso, a la fundación de la propia Atenas, ${ }^{81}$ había sido consagrado, tras seis siglos de obra interrumpida, por la máxima autoridad del Imperio, por el propio emperador en persona. Y gracias a la acción directa del emperador, aquel pedazo de suelo provincial había quedado convertido en auténtico suelo sagrado, sin necesidad de ninguna analogía, sin necesidad de ninguna ficción.

La ratificación material de la interpretación que aquí ofrezco, que Adriano, consagrando él mismo el templo de Zeus Olimpio en Atenas, había roto la barrera que separaba el suelo religioso romano del suelo tratado como si fuera religioso de las provincias, la ofrecen tres inscripciones que provienen del mismo templo. ${ }^{82}$ Se trata de las únicas tres basas inscritas en latín allí encontradas. Todas ellas llevan un texto similar en el que se proclamaba al emperador Olimpio y se daba la fecha de la decimosexta potestad tribunicia para el monumento, como ya sabemos, el año 131-132. Pero lo más significativo es que estas basas han sido levantadas por tres colonias de ciudadanos romanos, Dion, en Macedonia, Alejandría Tróade en Asia y Antioquía de Pisidia en Galatia. ${ }^{83}$ La importancia de estos actos es, a mi modo de ver, descomunal:

80. Sobre el poder de la analogía como instrumento de innovación jurídica y religiosa: Ando, 2009, pp. 99-113.

81. El testimonio más antiguo sobre el santuario de Zeus Olimpio es Thuc., II 15, 4, donde se afirma

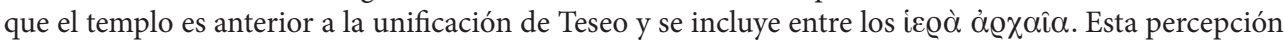
de antigüedad y sacralidad también aparece en el Marmor Parium, donde se atribuye el templo a Deucalión, Jacoby, 2004, pp. 4, 6-8.

82. Camia, Corcella y Monaco, 2018. Quiero agradecer a la profesora Monaco su generosidad al ofrecerme el texto todavía no publicado.

83. CIL III 7281 (= IG II' 3289), 7282, 7283. 
tres comunidades que podrían definirse como representaciones de Roma en las provincias ${ }^{84}$ estaban honrando al emperador en un templo de una polis griega, a la vez que lo proclamaban, también ellas, Olimpio. Colonias romanas, ciudades peregrinas, poleis griegas, ciudades libres, unidas todas ellas en el temenos de Zeus para celebrar a su emperador. Las puertas a un nuevo imperio ecuménico estaban abiertas.

La consagración del templo de Zeus Olimpio en Atenas atrajo el interés de historiadores, viajeros, biógrafos y literatos antiguos, tanto como ha captado la atención de viajeros, arqueólogos e historiadores modernos. Nosotros, los modernos, seguimos impresionados por las dimensiones colosales de un templo que sólo podemos ver completo en nuestra imaginación; y estamos dispuestos a creer que esa era la perspectiva antigua. Pero curiosamente ni Pausanias, ni Filóstrato, como tampoco la Historia Augusta o Casio Dion, ${ }^{85}$ se detuvieron en el tamaño descomunal del templo. No era eso lo que provocó el interés de los antiguos aunque - podemos estar seguros - hubiesen quedado maravillados al contemplarlo. Para unos fue la victoria sobre el tiempo lo memorable; para la mayoría fue la ceremonia de consagración; otros quisieron recordar las estatuas del emperador que allí se levantaron, colosales algunas, numerosísimas las más cercanas al natural. El valor religioso de templo, obviamente, era lo fundamental y este adquirió su pleno sentido en el hecho de que fue el primer templo consagrado por un emperador en suelo peregrino. La conclusión de aquella obra fue entendida como el indicio de la condición divina del emperador. Tras proclamar a Adriano como Olimpio, tras ser aceptado por griegos y romanos en tal condición, se aceleraron los pasos que conducían a un nuevo Imperio concebido como una comunidad religiosa universal.

84. Gell., NA XVI 13, 8.

85. Paus., I 18, 6-8; Philostr., VS I 533; HA, Hadr. 13, 6; Cass. Dio, LXIX 16, 1. 


\section{Bibliografía}

Ando, C. (2009). Diana on the Aventine. En Cancik y Rüpke, 2009, pp. 99-113.

Ando, C. (2015). Roman Social Imaginaries. Toronto: University of Toronto Press.

Benjamin, A.S. (1963). The altars of Hadrian in Athens and Hadrian's Panhellenic program. Hesperia, 32, pp. 57-86.

Birley, A.R. (1997). Hadrian. The Restless Emperor. London: Routledge.

Boatwrigh, M.T. (1987). Hadrian and the City of Rome. Princeton: Princeton University Press.

Bowie, E. (1971). The Temple of Hadrian at Ephesus. ZPE, 8, pp. 137-141.

Bowie, E. (2012). Hadrien et Éphèse. En Hostein y Lalanne, 2012, pp. 263-296.

Burrel, B. (2002-2003). Temples of Hadrian, not Zeus. GRBS, 43, pp. 44-48.

Burrell, B. (2004). Neokoroi. Greek Cities and Roman Emperors. Leiden: Brill.

Calandra, E. (1996). Oltre la Grecia. Perugia: Edizioni scientifiche italiane.

Callu, J.-P. (1992). Historie Auguste. Introduction générale. Vies d'Hadrien, Aelius, Antonin. Paris: Les Belles Lettres.

Camia, F., Corcella, A. y Monaco, M.C. (2018). Hadrian, the Olympieion and the foreign cities. En Di Napoli, V., Camia, F., Evangelidis, V., Grigoropoulos, D., Rogers, D., Vlizos, S. (eds.). What's new in Roman Greece (Meletemata 80). Athens: National Hellenic Research Foundation, Institute of Historical Research, pp. 477-486.

Cancik, H. y Rüpke, J. (eds.) (2009). Die Religion des Imperium Romanum, Tübingen. Mohr Siebeck.

Catalano, P. (1978). Aspetti spaziali del sistema giuridico-religioso romano. ANRW II, 16.1, pp. 440-553.

Cortés Copete, J.M. (2014). Mentiras de una adopción. En Marco, Pina y Remesal, 2014, pp. 187-208.

Cortés Copete, J.M. (2017a). Hadrian among the Gods. En Muñiz, Cortés y Lozano 2017, pp. 112-136.

Cortés Copete, J.M. (2017b). Governing by Dispatching Letters: The Hadrianic Chancellery. En Rosillo, C. (ed.). Political Communication in the Roman World (pp. 106-136). LeidenBoston: Brill

Drew-Bear, T. y Richard, Fr. (1994). Hadrien et Erastos, nauclère d'Éphèse. En L'Afrique, la Gaule, la Religion à l'époque romaine. Mélanges à la memoire de M. Le Glay (pp. 742751). Bruselles: Latomus. Revue d'études latines.

Eck, W. (1970). Senatoren von Vespasian bis Hadrian. München: C.H. Beck'sche Verlagsbuchhandlung.

Fishwick, D. (1987). The Imperial Cult in the Latin West. I, 1. Leiden: Brill.

Fishwick, D. (2002). The Imperial Cult in the Latin West. III, 1. Leiden: Brill.

Follet, S. (1976). Athènes au IIe et IIIe siècle. Paris: Les Belles Lettres.

Fündling, J. (2000). Die Macht der exempla. Hadrian als Militärreformer im Excurs Hadr. 10,2-11,1. HAC, 8, pp. 253-273. 
Fündling, J. (2006). Kommentar zur Historia Augusta. Band 4. Vita Hadriani. Bonn: Dr. Rudolf Habelt GmbH.

Geagan, D.J. (1979). Roman Athens I: Some Aspects of Life and Culture. ANRW, II 7.1, pp. 371-437.

Gordillo, R. (2012). La construcción religiosa de la Hélade imperial. Firenze: Firenze University Press.

Graf, F. (2015). Roman festivals in the Greek East. Cambridge: Cambridge University Press.

Graindor, P. (1914). “Inscriptions attiques d'époque impériale. BCH, 38, pp. 351-443.

Graindor, P. (1922). Chronologie des Archontes Athéniens sous l'Empire. Académie Royal de Belgique. Clase des Lettres. Mémoires Ser. 2, VIII. Bruxelles: Maurice Lamertin.

Graindor, P. (1934). Athènes sous Hadrien. Le Caire : Imprimerie nationale.

Habicht, Ch. (1969). Die Inschriften des Asklepieions. Berlin: De Gruyter.

Haensh, R. (ed.) (2009). Selbstdarstellun und Kommunikation. München: Beck.

Halfmann, H. (1986). Itinera Principum. Stuttgart: F. Steiner Verlag Wiesbaden.

Halfmann, H. (2004). Éphèse et Pergame. Bordeaux: Ausonius.

Hammond, M. (1959). The Antonine Monarchy. Rome: American Academy in Rome.

Hostein, A. y Lalanne, S. (eds.) (2012). Les voyages des empereurs dan l'Orient Romain. Arles: Editions Errance.

Jacoby, F. (2004). Das Marmor Parium. Berlín: Weidmann.

Jocelyn, H.D. y Hurt, H. (eds.) (1993). Tria Lustra. Liverpool Classical Papers III. Liverpool: Liverpool Classical Monthly.

Kuhlmann, P. (2002). Religion und Erinnerung. Die Religionspolitik Kaiser Hadrians und ihre Rezeption in der antiken Literatur. Göttingen: Vandenhoeck \& Ruprecht.

Kvium, Chr. (2011). Inauguration and Foundation. An Essay on Roman Ritual Classification and Continuity. En Richardson y Santangelo, 2011, pp. 63-90.

Le Bohec, Y. (2003). Les discours d'Hadrien à l'armée d'Afrique. Paris: De Boccard.

Linderski, J. (1986). The Augural Law. ANRW, II 16.3, pp. 2146-2312.

Marco, F., Pina, F. y Remesal, J. (eds.) (2014). Fraude, mentiras y engaños en el Mundo Antiguo. Barcelona: Universitat de Barcelona, Publicacions i Edicions.

Mrozek, S. (2004). Sur la 'dedicatio', la 'consecratio' et le dédicants dans les inscriptions du Haut-Empire romain. Epigraphica, 66, pp. 119-134.

Müller, H. (2009). Hadrian an die Pergamener. En Haensh, 2009, pp. 367-406.

Muñiz, E., Cortés, J.M. y Lozano, F. (eds.) (2017). Empire and Religion. Leiden: Brill.

Oliver, J.H. (1970). Marcus Aurelius. Aspects of civic and cultural policy in the East. Princeton: American School of Classical Studies at Athens.

Oliver, J.H. (1989). Greek Constitutions of Early Roman Emperors. Philadelphia: American Philosophical Society,.

Perret, L. (1929). La titulature impériale d'Hadrien. Paris: de Boccard.

Rich, J.W. (1993). The Foundation of the Altar of Roma and Augustus at Lugdunum. En Jocelyn y Hurt, 1993, pp. 191-201. 
Richardson, J.H. y Santangelo, F. (eds.) (2011). Priests and State in the Roman World. Stuttgart: F. Steiner.

Riemann, O. (1877). Inscriptions grecques provenant du receuil de Cyriaque d'Ancône. I. Manuscrit 996 de la bibliothèque Riccardienne à Florence. BCH, 1, pp. 286-294.

Sauciuc, Th. (1912). Ein Hadriansbrief und das Hadriansgynasium in Athen. AthMitt, 37, pp. 183-189.

Spawforth, A.J. y Walker, S. (1985). The World of the Panhellenion, I. JRS, 75, pp. 78-104. Syme, R. (1988), Journeys of Hadrian. ZPE, 73, pp. 159-170.

Talbert, R.J.A. (1984). The Senate of Imperial Rome. Princeton: Princeton University Press. Turcan, R. (1964). La fondation du temple de Venus et de Rome. Latomus, 23, pp. 42-55.

Weber, W. (1907). Untersuchungen zur Geschichte des Kaisers Hadrianus. Leipzig: B. G. Teubner.

Wörrle, M. (1992). Neue Inschriftenfunde aus Aizanoi I. Chiron, 22, pp. 337-349

Wycherley, R.E. (1964). The Olympieon at Athens. GRBS, 5, pp. 161-179. 